\title{
Politica Nacional de Práticas Integrativas e Complementares: trajetória e desafios em 30 anos do SUS
}

\author{
I 1 Gisléa Kândida Ferreira da Silva, ${ }^{2}$ Islândia Maria Carvalho de Sousa, \\ ${ }^{3}$ Maria Eduarda Guerra da Silva Cabral, ${ }^{4}$ Adriana Falangola Benjamin Bezerra, \\ ${ }^{5}$ Maria Beatriz Lisboa Guimarães I
}

Resumo: Este artigo analisa a construção e desenvolvimento da Política Nacional de Práticas Integrativas e Complementares (PNPIC) no SUS e seus antecedentes. O estudo envolveu revisão de literatura, análise documental e entrevistas com atores-chave no processo de construção e implementação da política. Apoiou-se no modelo de múltiplos fluxos proposto por Kingdon no que tange à formulação da agenda política. Os resultados apontam momentos importantes na trajetória da política: influência de parâmetros internacionais; papel das conferências nacionais de saúde na construção da demanda social; experiências iniciais de oferta na rede pública; protagonismo no âmbito do ensino e pesquisa; entrada na agenda política; condução federal e desafios para a institucionalização. A formulação da PNPIC ocorre pela pressão de atores estratégicos que empreenderam açóes em condiçōes institucionais favoráveis no âmbito do Ministério da Saúde após mudança política na esfera do Governo Federal em 2003, criando uma janela de oportunidade política. Tal processo foi marcado por resistências oriundas da racionalidade biomédica e disputas de interesses. Apesar do avanço relativo à disseminaçấo e visibilidade da oferta de serviços, as ações no âmbito da condução federal não foram acompanhadas por mudanças significativas na formação dos profissionais e nas práticas hegemônicas de saúde.

> Palavras-chave: medicina tradicional; terapias complementares; políticas públicas; política de saúde brasileira.

\author{
${ }^{1}$ Departamento de Saúde Coletiva, \\ Instituto Aggeu Magalhães, \\ Fundação Oswaldo Cruz, Recife- \\ PE, Brasil (gislea.psi@gmail.com). \\ ORCID: 0000-0002-5435-2306 \\ ${ }^{2}$ Departamento de Saúde \\ Coletiva, Instituto Aggeu \\ Magalhães, Fundação \\ Oswaldo Cruz, Recife-PE, Brasil \\ (islandia@cpqam.fiocruz.br). \\ ORCID:0000-0001-9324-4896 \\ ${ }^{3}$ Departamento de Medicina \\ Social, Universidade Federal de \\ Pernambuco, Recife-PE, Brasil \\ (mariaeduardaguerra@gmail.com). \\ ORCID: 0000-0001-9129-411X

\section{${ }^{4}$ Departamento de Medicina Social, Universidade Federal de Pernambuco, Recife, Brasil (afalangola@uol.com.br). ORCID: 0000-0002-5278-3727 \\ ${ }^{5}$ Departamento de Medicina Social, Universidade Federal de Pernambuco, Recife-PE, Brasil (mblguima@gmail.com). ORCID: 0000-0001-8554-600X}

Recebido em: 06/08/2019 Aprovado em: 12/08/2019 Revisado em: 23/03/2020 


\section{Introdução}

O debate em torno das Medicinas Tradicionais Complementares e Integrativas (MTCI) - denominadas no Brasil de Práticas Integrativas e Complementares em Saúde (PICS) - vem crescendo consideravelmente nas últimas décadas em muitos países (OMS, 2013), tanto de forma complementar à Biomedicina (BODEKER; BURFORD, 2007), quanto nas situaçôes em que são utilizadas para atender à maior parte das necessidades primárias em saúde, tal como ocorre em alguns países africanos (STEKELENBURG et al., 2005; KODURU; GRIERSON; AFOLAYAN, 2007).

No contexto das Américas, o Brasil foi um dos países pioneiros a reivindicar a inclusão social de tais práticas no sistema público de saúde, cujo marco constituiu a VIII Conferência Nacional de Saúde em 1986 (LUZ; BARROS, 2012). Contudo, o processo de oficialização das PICS culminou 20 anos depois, em 2006, com a publicação da Portaria no 971/2006 que criou a Política Nacional de Práticas Integrativas e Complementares (PNPIC) (BRASIL, 2006a).

A aprovação da PNPIC contribuiu para a visibilidade da oferta de serviços de PICS no país, demonstrada pelo aumento de serviços cadastrados, e também para o pluralismo terapêutico no SUS (SOUSA et al., 2012). No entanto, desde a sua aprovação, persistem entraves que repercutem na baixa institucionalização da política, como a inexistência de financiamento indutor e carência de profissionais.

Entre 2017 e 2018, a PNPIC ampliou o rol de sistemas complexos e recursos terapêuticos reconhecidos, com possibilidade de oferta no SUS: arteterapia, ayurveda, biodança, dança circular, meditação, musicoterapia, naturopatia, osteopatia, quiropraxia, reflexoterapia, reiki, shantala, terapia comunitária integrativa, yoga, aromaterapia, apiterapia, bioenergética, constelação familiar, cromoterapia, geoterapia, hipnoterapia, imposição de mãos, ozonioterapia e terapia de florais (BRASIL, 2017a; 2017b; 2018a), além das elencadas pela política: Medicina Tradicional Chinesa/acupuntura, homeopatia, plantas medicinais e fitoterapia, medicina antroposófica e termalismo-crenoterapia. A ampliação se deu num contexto político conturbado, com repercussões favoráveis e contrárias por parte de diferentes segmentos de interesse (TESSER; SOUSA; NASCIMENTO, 2018).

A partir da compreensão das políticas públicas em sua dimensão processual, e não apenas enquanto instrumento técnico, este artigo destina-se à análise da Política 
Nacional de Práticas Integrativas e Complementares no SUS, em seus aspectos históricos, políticos e institucionais. Busca apresentar algumas reflexóes acerca da emergência da proposta de uma política nacional de integração das PICS no SUS, bem como elementos de suas mudanças e permanências.

\section{Método}

A pesquisa ancorou-se no referencial de análise de políticas públicas, conforme o modelo de múltiplos fluxos de Kingdon (2011), para auxiliar na compreensão do processo de adoção de novas políticas públicas na agenda governamental. $\mathrm{O}$ modelo propóe que o processo de tomada de decisão nas políticas públicas pode ser representado pela confluência de três grandes fluxos: o fluxo dos problemas (problem streams), o das propostas ou alternativas (policy streams) e o da política (political streams).

O fluxo dos problemas refere-se ao reconhecimento que adquire um problema em um dado momento pela sociedade. O fluxo das propostas ou alternativas alude à existência de ideias que permitam modificar a compreensão do problema, podendo advir de atores sociais diversos, como especialistas, políticos, entidades em geral. $\mathrm{O}$ fluxo da política remete à existência de uma situação favorável no contexto político, administrativo e legislativo, ou seja, a existência de um clima político para a discussão e proposiçáo de soluçóes, levando em conta atores atrelados à esfera governamental e não governamental (KINGDON, 2011).

Um componente importante destacado no modelo dos múltiplos fluxos é a atuação de atores estratégicos prontos para operar quando uma janela de oportunidade política se abre, denominados de "empreendedores políticos". Estes podem ser oriundos do governo ou fora dele, compondo grupos de interesse ligados a diversos segmentos sociais, em geral especialistas ou figuras públicas dotadas de popularidade política (CAPELLA, 2007).

Partindo-se deste referencial teórico, analisaram-se os fluxos de eventos concernentes ao processo de formulação e desenvolvimento da PNPIC, tendo como marcos a VIII Conferência Nacional de Saúde e a publicação da Portaria 971/2006, que aprovou a PNPIC, envolvendo para tal articulaçôes de segmentos diversos entre gestão, órgãos de representação profissional e instituições acadêmicas, constituindose uma análise de 30 anos da institucionalização das PICS no SUS. 
A coleta de dados envolveu:

1) pesquisa documental, no período de 1986 até 2016, compreendendo os seguintes documentos: a - relatórios das conferências nacionais de saúde; b - texto da PNPIC; c - portarias, normas técnicas e outras produçóes do Ministério da Saúde; d - resumos executivos da Comissão Intergestores Tripartite; e - atas do Conselho Nacional de Saúde e f - relatórios de gestão da coordenação nacional da PNPIC;

2) entrevistas semiestruturadas com atores estratégicos no processo de formulação e desenvolvimento da PNPIC, totalizando 7 sujeitos entrevistados, envolvendo: a - 3 gestores e técnicos que atuaram junto à coordenação nacional da PNPIC no período analisado; b - 2 membros dos grupos de trabalho responsáveis pela sistematização das propostas incorporadas à PNPIC; c - 2 pesquisadores no tema em questão que contribuíram para a construção da política.

Os sujeitos entrevistados foram denominados de acordo com as categorias: gestores/técnicos; grupo de trabalho; e pesquisadores, preservando-se suas identidades, de acordo com a Resolução CNS 466/12. Na análise dos documentos todas as denominaçôes referentes às MTCI foram postas como PICS, visto que esta é a denominação oficial utilizada no Brasil.

A pesquisa foi aprovada pelo Comitê de Ética e Pesquisa da Fundação Oswaldo Cruz, Pernambuco, sob o parecer $n^{\circ}$ 1.695.553. Todos os sujeitos entrevistados participaram voluntariamente, tendo sido solicitada a assinatura do Termo de Consentimento Livre e Esclarecido.

\section{Resultados e Discussão}

\section{O fluxo dos problemas: eventos externos e internos na construção da demanda social pela integração das PICS no SUS}

$\mathrm{Na}$ análise do fluxo dos problemas, destacam-se no âmbito internacional o crescimento do uso de PICS no Ocidente e a definição de parâmetros de organismos internacionais. Com efeito, a importância das PICS no cuidado à saúde das populaçôes aparece claramente nos documentos da OMS. No Relatório de Alma Ata constata-se que o cuidado em saúde não é acessível a grande parcela da população mundial, produzindo desigualdades no estado de saúde inaceitáveis entre os povos. As práticas de cuidado em saúde provenientes de saberes tradicionais estão inscritas 
no campo dos cuidados primários, com estímulo à utilização dos recursos culturais e comunitários disponíveis (CONFERÊNCIA INTERNACIONAL..., 1978).

Desde a década de 1970, a OMS vem criando espaços de debates acerca das PICS, por meio do Programa de Medicina Tradicional criado em 1976 (BRASIL, 2005), estimulando a criaçấo de alternativas de cuidado frente aos altos custos dos sistemas de saúde para responder aos reflexos da transição demográfica e epidemiológica (OMS, 2013). De forma mais contundente, foi lançado um extenso documento em 2002 com a intenção de definir açôes estratégicas, preconizando investigaçôes sobre segurança, qualidade, eficácia, acesso e uso racional das PICS por profissionais e usuários, bem como políticas de integração nacional de tais práticas aos sistemas de saúde (OPAS, 2002).

Atualizado em 2013, o documento trouxe perspectivas de orientaçôes para o período 2014-2023 sobre os avanços globais acerca da utilização das PICS, no esforço de direcionar respostas a novas demandas relacionadas à regulamentação, avaliação de produtos e qualificação de profissionais (OMS, 2013). Com apoio técnico de centros nacionais de colaboração, como o National Center of Complementary and Integrative Health (NCCIH), nos EUA, a OMS tem contribuído com pareceres técnicos, produção de documentos e referências para métodos de pesquisa envolvendo as PICS. A OMS marca a sua influência, por meio do discurso promotor de estratégias de integração das PICS aos sistemas de saúde.

Além disso, outro aspecto importante situado no âmbito das crenças e preocupaçôes coletivas diz respeito ao retorno da valorização dos saberes e práticas de cuidado populares, fruto do processo de contestaçáo social no interior dos movimentos de contracultura impulsionados pela juventude americana e europeia durante os anos 60 e 70 (NASCIMENTO et al., 2013). O crescimento da oferta e uso das PICS também é associado ao reconhecimento dos limites da biomedicina em sua dependência da alta tecnologia, à deterioração da relação profissional-paciente, à desumanização das práticas e à ênfase diagnóstica (SANTOS; TESSER, 2012; SILVA; TESSER, 2013).

No Brasil, a partir dos anos de 1970, observou-se o crescimento do uso de terapias e medicinas não convencionais pelas classes médias urbanas. A inclusão das PICS como tema de interesse para a pauta social aconteceu em contexto de contestação da ditadura militar e defesa do estabelecimento do estado de direito e de um sistema público de acesso universal aos serviços de saúde (LUZ; BARROS, 2012). 
A primeira ação de institucionalização das PICS nos serviços públicos foi o convênio realizado em 1985 entre o INAMPS, a Fundação Oswaldo Cruz, a Universidade do Estado do Rio de Janeiro e o Instituto Hahnemanniano Brasileiro (IHB), onde se estabeleceram ações de atendimento médico envolvendo acupuntura, homeopatia e fitoterapia e também atividades de pesquisa (LUZ, 2005).

No âmbito da participação político-social, as Conferências de Saúde desempenharam importante papel na discussão e construção do SUS. O caminho da institucionalização das PICS no Brasil teve como importante marco a VIII Conferência Nacional de Saúde, em 1986. Dada a sua importância histórica e política, esta conferência apresentou as primeiras reivindicaçóes acerca da integração das PICS nos serviços públicos de saúde. O texto final trouxe como deliberação a "introdução de práticas alternativas de assistência à saúde no âmbito dos serviços de saúde, possibilitando ao usuário o acesso democrático de escolher a terapêutica preferida" (CNS, 1987, p. 10).

As Conferências subsequentes seguiram apresentando proposições que reforçavam a necessidade de integração de tais práticas no SUS como uma estratégia importante no redirecionamento do modelo assistencial, aprofundamento da integralidade do cuidado e de alargamento de opções terapêuticas, frente a um cenário de transição demográfica e epidemiológica (quadro 1).

Quadro 1. Conferências Nacionais de Saúde e Práticas Integrativas e Complementares. Brasil, 1986 a 2005

\begin{tabular}{|c|c|c|c|}
\hline Conferência & Ano & Tema & Proposiçóes acerca da integraçáo das PICS \\
\hline $\begin{array}{l}8^{\text {a }} \text { Conferência } \\
\text { Nacional de } \\
\text { Saúde }\end{array}$ & 1986 & $\begin{array}{l}\text { 1. Saúde como direito; } 2 . \\
\text { Reformulação do Sistema } \\
\text { Nacional de Saúde; e } 3 \text {. } \\
\text { Financiamento setorial }\end{array}$ & $\begin{array}{l}\text { “...introdução de práticas alternativas de } \\
\text { assistência à saúde no âmbito dos serviços } \\
\text { de saúde, possibilitando ao usuário o acesso } \\
\text { democrático de escolher a terapêutica } \\
\text { preferida” (CNS, 1987, p. 10). }\end{array}$ \\
\hline $\begin{array}{l}10^{a} \\
\text { Conferência } \\
\text { Nacional de } \\
\text { Saúde }\end{array}$ & 1996 & $\begin{array}{l}\text { 1. Saúde, cidadania e } \\
\text { políticas públicas; } 2 \text {. Gestão } \\
\text { e organização dos serviços } \\
\text { de saúde; } 3 \text {. Controle social } \\
\text { na saúde; } 4 \text {. Financiamento } \\
\text { da saúde; } 5 \text {. Recursos } \\
\text { humanos para a saúde; e } 6 \\
\text { Atenção integral à saúde. }\end{array}$ & $\begin{array}{l}\text { Aparecem pela primeira vez entre as } \\
\text { proposiçóes aprovadas três das racionalidades } \\
\text { e práticas terapêuticas que posteriormente } \\
\text { seriam incorporadas à PNPIC: fitoterapia, } \\
\text { acupuntura e homeopatia, denominadas } \\
\text { como terapias alternativas e práticas populares, } \\
\text { e a necessidade de sua incorporação no SUS } \\
\text { (CNS, 1998, p. } 73 \text { ). }\end{array}$ \\
\hline
\end{tabular}




\begin{tabular}{|c|c|c|c|}
\hline Conferência & Ano & Tema & Proposiçóes acerca da integraçáo das PICS \\
\hline $\begin{array}{l}\mathbf{1 1} \mathbf{a}^{\mathbf{a}} \\
\text { Conferência } \\
\text { Nacional de } \\
\text { Saúde }\end{array}$ & 2000 & $\begin{array}{l}\text { Efetivando o SUS - Acesso, } \\
\text { qualidade e humanizaçáo } \\
\text { na atenção à saúde com } \\
\text { controle social. }\end{array}$ & $\begin{array}{l}\text { Trouxe críticas aos modelos de atenção } \\
\text { vigentes como insuficientes para responder } \\
\text { às necessidades da população pela ênfase } \\
\text { curativista e médico-centrada que os } \\
\text { caracterizam. As PICS aparecem no } \\
\text { documento final desta Conferência } \\
\text { como "práticas não hegemônicas", sendo } \\
\text { representadas como alternativas assistenciais } \\
\text { mais baratas, eficazes, de potencial preventivo } \\
\text { e curativo, mas com pouco estímulo no país } \\
\text { (CNS, 2001). }\end{array}$ \\
\hline
\end{tabular}

\begin{tabular}{lll}
\hline 1a Conferência $^{\text {20 2001 }}$ & $\begin{array}{l}\text { Efetivar o Sistema Nacional } \\
\text { de Vigilância Sanitária: }\end{array}$ \\
Vigilância & & proteger e promover \\
Sanitária & $\begin{array}{l}\text { a saúde, construindo } \\
\text { cidadania. }\end{array}$
\end{tabular}

Deliberações acerca da regulação de medicamentos fitoterápicos e o estímulo a pesquisas com plantas nacionais, com vistas à oferta segura e eficaz à população, ampliando o acesso principalmente no âmbito da Atenção Básica (CONFERÊNCIA NACIONAL DE SAÚDE, 2001).

\begin{tabular}{lll}
\hline $12^{\text {a }}$ & 2003 & $\begin{array}{l}\text { Saúde: direito de todos e } \\
\text { dever do Estado; o SUS }\end{array}$ \\
Conferência & & que temos e o SUS que \\
Nacional de & queremos.
\end{tabular}

A efetiva implementação de práticas alternativas de saúde nos serviços do SUS (fitoterapia, reflexologia, homeopatia, acupuntura e massoterapia) é apontada como uma diretriz geral do sistema de saúde, destacando a importância da oferta de opçóes de cuidado para além da racionalidade biomédica. O texto recomenda ainda o incentivo a estudos sobre práticas de cuidado à saúde consideradas alternativas, holísticas, complementares e naturais, a normatização e reconhecimento das atividades dos facilitadores das "Práticas Integrativas em Saúde" (PIS) (CNS, 2004, p. 124) e a inserção da homeopatia, acupuntura e práticas integrativas em saúde como conteúdo de educação permanente para os profissionais de todas as categorias de saúde em todos os níveis de formação. 


\begin{tabular}{|c|c|c|c|}
\hline Conferência & Ano & Tema & Proposiçóes acerca da integraçáo das PICS \\
\hline $\begin{array}{l}\text { I Conferência } \\
\text { Nacional de } \\
\text { Medicamentos } \\
\text { e Assistência } \\
\text { Farmacêutica }\end{array}$ & 2003 & $\begin{array}{l}\text { Efetivando o acesso, a } \\
\text { qualidade e a humanização } \\
\text { na assistência farmacêutica, } \\
\text { com controle social }\end{array}$ & $\begin{array}{l}\text { Em todos os eixos temáticos que estiveram } \\
\text { em debate foram apresentadas propostas } \\
\text { envolvendo medicamentos homeopáticos e } \\
\text { fitoterápicos, abordando desde a educação } \\
\text { em saúde, açôes de financiamento, ampliação } \\
\text { da oferta, fomento a pesquisas, normatização } \\
\text { de serviços, bem como a necessidade de } \\
\text { elaboração de uma política nacional de plantas } \\
\text { medicinais e fitoterápicos (CNMAF, 2005). }\end{array}$ \\
\hline $\begin{array}{l}\text { II Conferência } \\
\text { Nacional } \\
\text { de Ciência, } \\
\text { Tecnologia e } \\
\text { Inovação em } \\
\text { Saúde }\end{array}$ & 2004 & $\begin{array}{l}\text { Produzir e aplicar } \\
\text { conhecimento na busca } \\
\text { da universalidade e } \\
\text { equidade, com qualidade da } \\
\text { assistência para a saúde da } \\
\text { populaçáo. }\end{array}$ & $\begin{array}{l}\text { Inclui tanto os medicamentos fitoterápicos } \\
\text { quanto os homeopáticos em várias } \\
\text { deliberaçóes do conjunto de prioridades } \\
\text { em temas como: desenvolvimento } \\
\text { de medicamentos para doenças não } \\
\text { transmissíveis relevantes para a saúde } \\
\text { pública; desenvolvimento de pesquisas } \\
\text { clínicas e estudos sobre atençáo em saúde } \\
\text { (CNCTIS, 2005). }\end{array}$ \\
\hline
\end{tabular}

Fonte: As autoras. Retirado de: CNS (1987, 1998, 2001, 2004); CNVS (2001); CNMAF (2005) e CNCTIS (2005).

Desde a década de 1980, experiências diversas de implantação de serviços de PICS no SUS, no âmbito dos estados e municípios, foram instauradas de forma desigual e descontinuada devido à falta de regulamentação (BRASIL, 2006a). Estudo realizado com municípios selecionados que desenvolveram experiências antes da PNPIC apontam que estas se davam impulsionadas quase sempre pelo pioneirismo e esforço voluntário de profissionais que trabalhavam nos respectivos serviços de saúde, na maioria das vezes atuando a partir de "acordos informais" com os gestores (SOUSA et al., 2012; SOUSA, 2013).

Nesse contexto, o Brasil reuniu experiências de inserção de PICS sob múltiplas combinações. Na Atenção Primária, o município de Campinas-SP implementou um programa de saúde integrativa ainda em 1989 (SOUSA; TESSER, 2017). Em Recife-PE e Macapá-AP desenvolveram-se experiências de serviços especializados de PICS, sendo o Recife um município com uma experiência singular por meio do Núcleo de Apoio às PICS (SANTOS et al., 2011; RÉCIO, 2010). Em SantosSP, houve a implantação de serviços de homeopatia por atores que não atuavam diretamente no sistema público de saúde (JUSTO; GOMES, 2007). 
Em 1999, a publicação da Portaria GM no 1.230/99 do Ministério da Saúde possibilitou o acompanhamento do primeiro indicador de monitoramento da oferta de PICS no SUS, por meio do registro das consultas médicas em homeopatia e acupuntura, além do repasse financeiro aos municípios por consultas realizadas. $\mathrm{O}$ Ministério da Saúde, de alguma forma, não ficava indiferente a essas experiências; contudo, não havia uma política abrangente e norteadora para as PICS no SUS, que só veio a ser promulgada em 2006, por meio da Portaria Ministerial 971 - a Política Nacional de Práticas Integrativas e Complementares - PNPIC.

As Conferências Nacionais de Saúde realizadas em 2008, 2011 e 2015, após a aprovação da PNPIC, trouxeram propostas que reafirmaram a necessidade de fortalecimento e implementação da política em todo o país. Articulação intersetorial, pactuação orçamentária entre os três níveis de governo e utilização de recursos da Atenção Básica foram apresentadas como propostas alternativas para execução orçamentária da política.

Nos relatórios das Conferências Nacionais de Saúde (quadro 1), da oitava (1986) à décima quinta (2015), registra-se a relação próxima entre as práticas integrativas e complementares e a consolidação e o aprofundamento dos princípios do SUS. Várias deliberaçôes apontaram para a necessidade de a política de saúde brasileira compreender e inserir em suas açóes o pluralismo terapêutico que é anunciado pela integração das PICS no SUS, conforme registrou um ator estratégico:

Então a gente se juntou, né? Vamos nos unir pra chamar essa empreitada de fazer uma política e convencer da necessidade e também se baseando, claro, nas Conferências $\mathrm{Na}$ cionais de Saúde, que desde a VIII Conferência de 86 já tinha um parágrafo de indicativo nos relatórios finais da necessidade de ampliação do que se chamava na época de medicina alternativa, né? E aí citavam já em duas conferências, se eu não me engano, a VIII com certeza e depois posteriormente, entáo era uma coisa que reiteradamente as conferências nacionais de saúde apontavam para essa necessidade, porque as experiências que aconteciam já tinham um público, já tinham um impacto perante a população e aí elas eram lembradas nos debates das conferências. Então isso também nos deu força para poder nos autorizar a chegar pro ministro e falar "olha, as conferências já apontam, nós já estamos aí antes e depois." No Rio de Janeiro já tinha, já se fazia homeopatia, já se tinha essas práticas, então a gente ganhou força nisso (Participante 6 - Segmento Grupo de Trabalho).

Assim, os problemas que levaram à inserção das PICS na política de saúde brasileira basearam-se essencialmente na constatação da necessidade de fortalecimento de tais práticas no SUS, promovendo uma abertura de opçóes 
terapêuticas, com vistas a uma saúde integral, tal como preconizava a OMS. Para tal, foi preciso traçar alternativas diante das açóes disponíveis.

\section{O fluxo das propostas: a construção de um discurso de legitimação das PICS no SUS}

Tomando o fluxo das soluçóes e alternativas como a existência de ideias que permitam modificar a compreensão do problema, destacam-se alguns eventos que produziram efeitos de legitimação e aceitação das PICS na política de saúde brasileira.

No âmbito do protagonismo no ensino e na pesquisa, o trabalho desenvolvido pelo grupo de pesquisa "Racionalidades em Saúde: sistemas médicos complexos e práticas complementares e integrativas" constituiu um evento importante na trajetória de institucionalização das PICS no SUS. Os estudos desenvolvidos pelo grupo possibilitaram romper uma barreira epistemológica que colocava em desnível outros sistemas complexos externos à biomedicina (LUZ, 2012).

A repercussão relativa à legitimação de diferentes racionalidades impulsionou o debate político e institucional que se desdobrou na formulaçấo da PNPIC, pela interface estabelecida entre integrantes do grupo e atores estratégicos no âmbito do Ministério da Saúde:

Bem, eu entendo que o grupo Racionalidades Médicas coordenado pela professora Madel foi um ator importante na construção da política. A política inclusive referência no seu texto o trabalho de produçáo do grupo e o grupo tinha interface. Além de ele reunir pesquisadores de diversos estados, diversas regióes do país, ele tinha uma interface com quem estava na época da edição da política à frente dessa área técnica do Ministério da Saúde [...]. Então eu acredito que o grupo teve esse papel, né? (Participante 1 - Segmento Pesquisadores).

O acúmulo de experiências de oferta de PICS em todas as regiôes do país, aliado à emergência de um novo entendimento sobre o tema, constituiu as bases de articulação para a ação de atores envolvidos na defesa de uma política das PICS de abrangência nacional.

Destaca-se a atuação de membros das sociedades e associaçôes médicas ligadas à Medicina Tradicional Chinesa/acupuntura, homeopatia, medicina antroposófica e fitoterapia como empreendedores políticos (CAPELA, 2007; SABATIER; WEIBLE, 2014) na difusão de uma mensagem acerca da integração oficial das PICS na política de saúde brasileira. Alguns desses atores atuavam no Ministério, em grande parte no Departamento de Atenção Básica, e propuseram uma reunião em 2003, com o 
então ministro da Saúde, Humberto Costa, para a construção da proposta de uma política nacional de fortalecimento das PICS:

E assim, uma coisa que poucas pessoas notam e que está escrito lá no texto da Política é que assim, quem fez a solicitação ao ministro de criação de uma política nacional foram as associações médicas. Então as associações médicas e aí muito as práticas médicas, que também faziam parte do conhecimento da medicina, faziam essa pressão junto ao ministro e isso foi primordial para que se tivesse uma política ministerial. Então talvez naquela época se fosse uma demanda somente da população ou das práticas populares de saúde, ou de tantos grupos que trabalham com práticas integrativas, talvez a gente não tivesse uma política nacional, mas como foi uma demanda das associaçóes médicas, isso teve um impacto, né? Uma aceitabilidade no ministério muito grande, apesar da resistência também, muito grande (Participante 5 - Segmento Gestores/técnicos).

É importante frisar que o ministro da Saúde à época foi secretário de Saúde do Recife, período no qual foi implantado um serviço especializado de PICS (SANTOS, 2011). O ministro é reconhecido como ator crucial na entrada da pauta da PICS no Ministério da Saúde, em termos de conteúdo e processo. A importância da reunião de 2003 e de seu papel é apresentada nas falas de alguns sujeitos entrevistados:

E aí a gente apostou mesmo, chamamos essas entidades, da fitoterapia nós chamamos algumas universidades, a Medicina Tradicional Chinesa, Medicina Antroposófica e nós da Homeopatia e fomos procurar o ministro, que era o Humberto Costa, e aí ele gostou muito da ideia de primeira, a gente ficou até surpreendido, né? Poxa, não sabia que era tão fácil. Por que a gente já não veio antes? Mas a gente tinha todo o argumento, de mostrar as conferências, que na verdade a gente estava só mostrando o que já tinha aí de demanda e aí ele falou "vamos fazer um grupo de trabalho então", e aí ele convocou a secretária executiva, pra ela ficar nos apoiando. Então foi um grupo de trabalho montado praticamente dentro do gabinete do ministro, né? Com apoio. Então ela foi gestada na hora certa, no momento certo, na gestão certa (Participante 6 - Segmento Grupo de Trabalho).

Integraram o grupo de trabalho representantes das Secretarias de Ciência, Tecnologia e Insumos Estratégicos e de Gestão do Trabalho e Educação na Saúde/ MS; Agência Nacional de Vigilância Sanitária (Anvisa); e Associações Brasileiras de Fitoterapia, Homeopatia, Acupuntura e Medicina Antroposófica. Como desdobramento, foram criados 4 subgrupos de trabalho correspondentes a cada racionalidade médica e recursos terapêuticos, tendo em vista as singularidades de cada prática.

O plano de ação pactuado foi de que os grupos seguiriam as discussões de forma independente para que, após esse trabalho, as diretrizes para cada racionalidade/ 
recurso terapêutico fossem unificadas em um único documento. Assim, cada grupo adotou sua estratégia de articulação, envolvendo criação de fóruns, reuniōes técnicas, oficinas, entre outras ações:

$\mathrm{Na}$ época, a gente pensava cada uma das práticas de forma separada, então a gente se juntava em alguns momentos, mas a gente não tinha uma estratégia de ação coletiva [...]. A partir desses encontros é que a gente começou a demandar ao Ministério da Saúde alguns encontros pra se tentar formular algo que fosse de certa forma a garantia de que o Ministério ajudaria a uma sistematizaçáo dessa inserção (Participante 2 - Segmento Grupo de Trabalho).

Os atores que estavam naquele momento mobilizando as discussôes acumulavam experiência acadêmica em PICS, gestão em âmbito estadual, municipal e compunham naquele momento o corpo técnico do Ministério da Saúde, em sua maioria ligados ao Departamento de Atenção Básica. O desenvolvimento de experiências diversas em PICS em todo o Brasil anterior à edição da política, aliado às características do corpo técnico que compunha o grupo de trabalho, constitui elemento importante que auxilia na compreensão da ênfase das PICS na Atenção Primária em Saúde (APS) que caracteriza a experiência brasileira.

A primeira ação do grupo de trabalho foi um diagnóstico da oferta de PICS no SUS, em 2004, nos 5.560 municípios. Foram identificados 232 municípios com oferta de alguma PIC, incluindo todas as capitais, com presença predominante na APS (MINISTÉRIO DA SAÚDE, 2004; BARROS; SIEGEL; DE SIMONI, 2007).

O uso estratégico de geração de conhecimento por meio de uma pesquisa nacional foi importante para promover posição política e consolidar argumentos de defesa das PICS para os segmentos contrários à sua integração no SUS. Tais experiências se multiplicaram pelo país, registrando-se, em 2017, 3.018 municípios com alguma oferta de PICS. Na APS, aproximadamente 19\% das unidades básicas de saúde ofertam algum tipo de atendimento em PICS (BRASIL, 2018b). A APS segue como estratégica até os dias de hoje, sendo os profissionais de saúde os agentes que mais têm promovido a expansão das PICS no SUS (TESSER; SOUSA; NASCIMENTO, 2018).

No entanto, para que a corrente das soluções se concretizasse, seria necessário um contexto político favorável, conforme postulado no Modelo de Kingdon (2011), capaz de confluir os múltiplos fluxos. Esses aspectos constituem o fluxo político. 


\section{O fluxo político: os caminhos da construção da Política Nacional de Práticas Integrativas e Complementares no SUS}

A terceira corrente de fluxos, que condiciona a abertura da janela de oportunidade na disputa do processo político, foi favorecida por um ambiente propício à mudança, caracterizado pela chegada ao poder de uma coalizáo de centro-esquerda democrática no governo federal, em 2003.

Com relação especificamente ao setor saúde, "havia uma expectativa que o governo Lula fortalecesse o projeto de reforma sanitária que foi questionado nos anos 90 " (BRAVO, 2006, p. 16) e que vinha sendo secundarizado pelo Ministério da Saúde. A despeito das contradiçôes existentes no governo Lula na condução do setor de saúde, destacam-se algumas inovaçôes, entre elas a escolha de profissionais comprometidos com a reforma sanitária para ocupar cargos no Ministério da Saúde (BRAVO, 2006).

Naquele momento, era um momento muito oportuno pra tudo isso acontecer. Era eleição do presidente Lula, era um momento do país muito esperançoso para coisas novas. Um fato importantíssimo é que Lula se tratava com a Medicina Chinesa, então tínhamos desde o Palácio do Planalto uma aderência [favorecendo] que isso pudesse ser ofertado no SUS (Participante 3 - Segmento Gestores/técnicos).

[...] Eu acho que foi um momento muito propício e certamente a união dessas coisas: a abertura a novas ideias, a um novo formato de cuidado e, lógico, em função também de muitos dados que mostravam uma falência daquele modelo tradicional (Participante 2 Segmento Grupo de Trabalho).

A partir daí, iniciou-se um movimento de articulação que propiciou a abertura da discussão no Ministério da Saúde de uma política de abordagem nacional das PICS no SUS, por meio da articulação entre atores estratégicos: associações profissionais, pesquisadores, gestores, profissionais de saúde e técnicos ministeriais. Após dois anos, em 2005, a proposta inicial do texto apresentada como resultado do grupo de trabalho foi submetida à análise das instâncias avaliadoras das Câmaras Técnicas dos Conselhos Nacionais de Secretários Estaduais e Municipais de Saúde e pactuada na Comissão Intergestores Tripartite (CIT).

A CIT aprovou o texto, mas com uma importante ressalva: a política não contaria com recurso financeiro indutor. Tal fato contrariava uma tendência histórica do Ministério da Saúde no financiamento de políticas nacionais e sinalizava um descompromisso da CIT com a nova política. Apesar de uma janela macropolítica favorável, havia resistências para legitimar a PNPIC, visto que uma política com essas características poderia afetar diferentes interesses que atravessam o setor de saúde. 
Ela vai primeiro pra Tripartite (a Comissão Intergestores Tripartite) e ela faz o quê? Diz "Ah, tudo bem, a gente aprova desde que não tenha nenhum recurso pra essa política". Daí a gente ouve a verdade do que você perguntou: É nenhuma (vontade política), de nenhum gestor municipal, estadual, federal. Nenhuma. (Participante 3 - segmento gestores/técnicos).

A passagem do texto para apreciação do Conselho Nacional de Saúde (CNS) (CONSELHO NACIONAL DE SAÚDE, 2005a) marcou a atuação de outros atores: representantes do CNS, técnicos do Ministério da Saúde ligados à Secretaria de Gestão do Trabalho e da Educação em Saúde (SEGTES), consultores externos que contribuíram no processo de revisão do texto da política e, em especial, membros do Fórum Nacional de Trabalhadores da Área da Saúde (FENTAS).

O FENTAS é uma comunidade política orientada pelos princípios do SUS e pela defesa de oferta pública de serviços de saúde e de direitos trabalhistas de profissionais não médicos (CÔRTES, 2009). Naquele momento, o FENTAS articulou uma aliança de entidades que perceberam uma tendência nas discussóes de privilegiar a categoria médica, e passou a defender a composição multiprofissional no exercício das PICS no SUS. Nesse momento, divergências acerca de alguns temas centrais surgiram e junto com elas foram construídas alternativas de açôes:

Pra o start da política eu consideraria como atores importantes as associaçóes médicas, mas, por exemplo, em 2003, tinha na Secretaria de Gestão da Educação e do Trabalho um grupo que discutia educação popular também e que foi um dos grupos que participou [sic] da discussão do GT da criação da política. Então eu digo que foram atores importantes naquele momento e que fizeram bastante pressão para que outras práticas entrassem na PNPIC e eu acho que essa pressão fez com que a política se fortalecesse no campo teórico dela, do que seria a política de práticas. [...] E o outro que eu citaria com certeza é o próprio Conselho Nacional de Saúde. E dentro do Conselho Nacional de Saúde as outras associaçóes de profissionais, eles tiveram um papel importantíssimo, dentre eles o próprio FENTAS. E eles fizeram uma pressão muito forte para que a política fosse multiprofissional (Participante 5 - Segmento Gestores/Técnicos).

O primeiro ponto foi relativo à multiprofissionalidade do exercício da acupuntura. As críticas pontuavam o viés corporativo da categoria médica (BRASIL/CNS, 2005a), sendo este tensionamento destacado por alguns dos entrevistados como um dos pontos marcantes da construçáo do texto final da PNPIC e que persiste mesmo após mais de dez anos de edição da política.

Eu acho que os maiores embates, as maiores divergências, sempre foram relacionadas a quem teria competência, quem seria o profissional habilitado a ser um profissional do 
SUS desempenhando aquela prática. Isso aconteceu principalmente na acupuntura e se estende até hoje. Então isso é uma questão que ainda não está resolvida. (Participante 2 - Segmento Grupo de Trabalho).

Outro elemento divergente foi em relação ao próprio nome da política. O conselheiro representante do Conselho Federal de Medicina (CFM) propôs a mudança de "política de medicina natural" para "política de medicina integrativa", sob o argumento de que a medicina integrativa "consiste na medicina que utiliza o conhecimento científico convencional agregado ao conhecimento tradicional, milenar ou centenário, também científico, excluindo práticas alternativas baseadas em crendices, mitos e magias" (Fala do representante do CFM - CNS, 2005a).

O FENTAS apresentou a proposta de alteração do nome da política para "Política Nacional de Práticas Complementares na Saúde” e inclusão de profissionais de saúde que tinham habilitação e regulamentação para executar as práticas da medicina tradicional chinesa/acupuntura, homeopatia, fitoterapia e medicina antroposófica.

A expressão "práticas alternativas" foi considerada inadequada, uma vez que remete à ideia de substituição de modelos, e se destacou também a necessidade de valorização de práticas tradicionais brasileiras, como as indígenas e as afro-brasileiras (CONSELHO NACIONAL DE SAÚDE, 2005a). A expressão "práticas integrativas e complementares", além da implícita relação de hierarquia com a biomedicina sendo esta complementar à medicina hegemônica -, apresenta ainda uma limitação no que se refere à inclusão de saberes e práticas da medicina tradicional do país (MOEBUS; NUNES, 2015), tema que continua a demandar maior aprofundamento.

As proposições apresentadas pelo FENTAS foram aceitas na $161^{\text {a }}$ reunião do CNS, definindo-se a mudança no nome da política para "Política Nacional de Práticas Integrativas e Complementares no SUS". O termo "integrativas", reivindicado pelo CFM, foi inserido. Desse modo, atendeu-se à proposição da categoria médica e incluiu-se também a prerrogativa da ação multiprofissional.

A inclusão do termalismo social e da crenoterapia, bem como a medicina antroposófica, na política aconteceu sob o formato de observatório de práticas. $\mathrm{O}$ termalismo teve como importante personagem a conselheira Zilda Arns, que, além da sugestão de inclusão, enviou um documento com as diretrizes sobre o termalismo na $161^{\text {a }}$ reuniáo ordinária do CNS, as quais foram incorporadas ao texto da política (CONSELHO NACIONAL DE SAÚDE, 2005b). 
A inclusão da medicina antroposófica como observatório de práticas foi justificada pela incipiente representatividade dessa abordagem médico-terapêutica, apesar do êxito das experiências conhecidas à época em Minas Gerais e São Paulo. O que, no entanto, não impediu a desconfiança das entidades de representação da categoria médica:

A gente sabe que a medicina antroposófica, ela não fosse... ela náo tinha o mesmo status
que a medicina chinesa/acupuntura, a fitoterapia e a homeopatia tinham perante o CFM,
por exemplo, que já reconhecia como especialidade médica. Já a medicina antroposófica,
o médico antroposófico ainda não era reconhecido dentro do CFM. A gente achou que
isso pudesse atrapalhar, mas vimos que não porque é uma prática que trazia um impacto
muito positivo e de uma experiência muito importante em Goiânia (Participante 6 - Seg-
mento Grupo de Trabalho).

O documento final da política sob a forma de Portaria Ministerial no 971 foi aprovado em 3 de maio de 2006, com o título "Política Nacional de Práticas Integrativas e Complementares no SUS", com as alteraçóes solicitadas pelo CNS. Os membros do CNS e das diversas entidades envolvidas com as PICS tiveram papel fundamental na revisão do texto original da política, embora a decisão política de não vinculação de recurso indutor durante a passagem pela CIT revele que as comissôes intergestores afetam negativamente a capacidade do CNS em consolidarse como arena central de decisão sobre a política nacional de saúde, como discutido por Côrtes (2009).

Com a publicação da política, o Departamento de Atenção Básica (DAB) do Ministério da Saúde passou a responder pela conduçáo federal da PNPIC, desempenhando o papel de monitoramento, normatização, sensibilização e divulgação de informações sobre a política. Nos últimos anos, a política esteve sob gestão da Coordenação Geral de Áreas Técnicas (CGAT/DAB) do DAB. Atualmente, as PICS integram a Coordenação Geral de Gestão da Atenção Básica (CGGB/DAB).

A institucionalização das PICS no SUS envolveu até o momento a publicação de 11 atos normativos com vistas à visibilidade, ao monitoramento e à normatização da oferta (quadro 2). 
Quadro 2. Atos Normativos relacionados à Política Nacional de Práticas Integrativas e Complementares. Brasil, 2006 a 2018

\begin{tabular}{|c|c|c|c|}
\hline Ano & Natureza da ação & Título & Resumo \\
\hline 2006 & $\begin{array}{l}\text { Portaria no } 853 / \\
\text { GM/MS }\end{array}$ & $\begin{array}{l}\text { Inclui na Tabela de Serviços/ } \\
\text { classificaçōes do Sistema de Cadastro } \\
\text { Nacional de Estabelecimentos de } \\
\text { Saúde - SCNES/SUS - as seguintes } \\
\text { classificaçōes: } 001 \text { - Acupuntura; } \\
002 \text { - Fitoterapia; } 003 \text { - Outras } \\
\text { Técnicas em Medicina Tradicional } \\
\text { Chinesa; } 004 \text { - Práticas Corporais/ } \\
\text { Atividade Física; } 005 \text { - Homeopatia; } \\
006 \text { - Termalismo/Crenoterapia; } 007 \\
\text { - Medicina Antroposófica. }\end{array}$ & $\begin{array}{l}\text { Possibilitou o registro de } \\
\text { profissionais, serviços e } \\
\text { produção relativas às PICS, o } \\
\text { que até então só era possível } \\
\text { em relação às consultas em } \\
\text { homeopatia e acupuntura. }\end{array}$ \\
\hline 2008 & $\begin{array}{l}\text { Portaria no } 154 / \\
\text { GM/MS }\end{array}$ & $\begin{array}{l}\text { Cria os Núcleos de Apoio à Saúde da } \\
\text { Família - NASF. }\end{array}$ & $\begin{array}{l}\text { Inclusáo do médico } \\
\text { acupunturista e do médico } \\
\text { homeopata no rol de } \\
\text { profissionais que podem atuar no } \\
\text { NASF. Representa um estímulo } \\
\text { à transversalidade das PICS em } \\
\text { outras estratégias e políticas. }\end{array}$ \\
\hline 2009 & $\begin{array}{l}\text { Caderno de } \\
\text { Atenção Básica } \\
\text { no } 27\end{array}$ & $\begin{array}{l}\text { Diretrizes do Núcleo de Apoio à } \\
\text { Saúde da Família }\end{array}$ & $\begin{array}{l}\text { Primeiro Caderno de Atençáo } \\
\text { Básica (CAB) com um capítulo } \\
\text { dedicado às PICS. }\end{array}$ \\
\hline 2009 & Portaria $n^{\circ} 84$ & $\begin{array}{l}\text { Adequa o serviço especializado } 134 \text { - } \\
\text { Serviço de práticas integrativas e sua } \\
\text { classificação } 001 \text { - Acupuntura }\end{array}$ & $\begin{array}{l}\text { Adequou o serviço de } \\
\text { acupuntura à inclusão das } \\
\text { ocupaçóes enfermeiro, } \\
\text { biomédico, fisioterapeuta } \\
\text { acupunturista, psicólogo } \\
\text { clínico-psicólogo, acupunturista } \\
\text { e farmacêutico na Classificação } \\
\text { Brasileira de Ocupações (CBO). }\end{array}$ \\
\hline 2010 & $\begin{array}{l}\text { Portaria no } 4.217 / \\
\text { GM/MS }\end{array}$ & $\begin{array}{l}\text { Inclui os medicamentos } \\
\text { homeopáticos da Farmacopeia } \\
\text { Homeopática Brasileira e alguns } \\
\text { fitoterápicos no Elenco de Referência } \\
\text { da Assistência Farmacêutica na } \\
\text { Atençáo Básica }\end{array}$ & $\begin{array}{l}\text { Aprovaçáo de normas de } \\
\text { financiamento e a execução } \\
\text { do Componente Básico da } \\
\text { Assistência Farmacêutica com } \\
\text { vistas a ampliar o acesso a } \\
\text { medicamentos fitoterápicos } \\
\text { no SUS, todos passíveis de } \\
\text { financiamento com recursos } \\
\text { tripartite. }\end{array}$ \\
\hline
\end{tabular}




\begin{tabular}{|c|c|c|c|}
\hline Ano & Natureza da açáo & Título & Resumo \\
\hline 2012 & $\begin{array}{l}\text { Relação Nacional } \\
\text { de Açóes e } \\
\text { Serviços do SUS } \\
\text { (RENASES) }\end{array}$ & $\begin{array}{l}\text { Incluiu ações de PICS no rol das } \\
\text { ações e serviços da Atenção Primária }\end{array}$ & $\begin{array}{l}\text { Reconhecimento das PICS } \\
\text { como estratégia de ampliação do } \\
\text { escopo da Atenção Básica }\end{array}$ \\
\hline 2012 & $\begin{array}{l}\text { Caderno de } \\
\text { Atenção Básica } \\
\text { no } 31\end{array}$ & $\begin{array}{l}\text { Plantas medicinais e fitoterápicos na } \\
\text { Atenção Básica }\end{array}$ & $\begin{array}{l}\text { Primeiro CAB dedicado } \\
\text { integralmente a uma das PICS } \\
\text { elencadas na PNPIC }\end{array}$ \\
\hline 2015 & $\begin{array}{l}\text { Relação Nacional } \\
\text { de Medicamentos } \\
\text { Essenciais } \\
\text { (RENAME) }\end{array}$ & $\begin{array}{l}\text { Foram inseridos } 12 \text { fitoterápicos, } \\
\text { além de toda a farmacopeia } \\
\text { homeopática brasileira }\end{array}$ & $\begin{array}{l}\text { Possibilidade de os municípios } \\
\text { brasileiros utilizarem recursos } \\
\text { do componente da Assistência } \\
\text { Farmacêutica Básica para } \\
\text { aquisiçáo de medicamentos } \\
\text { fitoterápicos, mediante } \\
\text { pactuação entre gestores } \\
\text { estaduais e municipais }\end{array}$ \\
\hline 2017 & Portaria No 145 & $\begin{array}{l}\text { Altera procedimentos na Tabela } \\
\text { de Procedimentos, Medicamentos, } \\
\text { Órteses, Próteses e Materiais } \\
\text { Especiais do SUS para atendimento } \\
\text { na Atenção Básica. }\end{array}$ & $\begin{array}{l}\text { Inclusão de oito práticas } \\
\text { integrativas na tabela de } \\
\text { procedimentos do SUS }\end{array}$ \\
\hline 2017 & Portaria No 849 & $\begin{array}{l}\text { Inclui a Arteterapia, Ayurveda, } \\
\text { Biodança, Dança Circular, Meditação, } \\
\text { Musicoterapia, Naturopatia, } \\
\text { Osteopatia, Quiropraxia, } \\
\text { Reflexoterapia, Reiki, Shantala, } \\
\text { Terapia Comunitária Integrativa e } \\
\text { Yoga à Política Nacional de Práticas } \\
\text { Integrativas e Complementares. }\end{array}$ & $\begin{array}{l}\text { Ampliação das práticas } \\
\text { integrativas e complementares } \\
\text { contempladas na PNPIC. }\end{array}$ \\
\hline 2018 & Portaria no 702 & $\begin{array}{l}\text { Inclui aromaterapia, apiterapia, } \\
\text { bioenergética, constelação } \\
\text { familiar, cromoterapia, geoterapia, } \\
\text { hipnoterapia, imposiçáo de mãos, } \\
\text { medicina antroposófica/antroposofia } \\
\text { aplicada à saúde, ozonioterapia, } \\
\text { terapia de florais à PNPIC. }\end{array}$ & $\begin{array}{l}\text { Ampliação das práticas } \\
\text { integrativas e complementares } \\
\text { contempladas na PNPIC. }\end{array}$ \\
\hline 2018 & $\begin{array}{l}\text { Publicação do } \\
\text { Ministério da } \\
\text { Saúde }\end{array}$ & $\begin{array}{l}\text { Guia de implantação de serviços } \\
\text { de práticas integrativas e } \\
\text { complementares no SUS. }\end{array}$ & $\begin{array}{l}\text { Orientações sobre implantação } \\
\text { e cadastramento de serviços de } \\
\text { PICS no SUS no SCNES. }\end{array}$ \\
\hline
\end{tabular}

Fonte: As autoras. Retirado de: Brasil (2006b, 2008, 2009a, 2009b, 2010, 2012a, 2012b, 2015, 2017a, 2017b, 2018a, 2018b). 
O desenvolvimento de tais ações no âmbito da condução federal da PNPIC não ocorreu sem a existência de dificuldades que envolvem o náo reconhecimento e priorização da PNPIC por parte do próprio Departamento de Atenção Básica:

Como é que o Departamento que tinha a política dentro dele não dava tanta prioridade, sendo que ela era reconhecida e estava cada vez mais sendo implementada nos municípios e estados. Então isso causa uma estranheza, né? (Participante 7 - Segmento Gestores/técnicos).

A publicação da portaria não colocou a PNPIC entre as prioridades da política de saúde brasileira. Tal como afirma Secchi (2015), o fortalecimento de uma alternativa pública depende do reconhecimento do status quo como inadequado e da expectativa de alcance de uma situação melhor.

\section{Percalços e perspectivas}

Vale destacar em relação aos atos normativos publicados (quadro 2), que tais açóes suscitam a visibilidade das PICS, permitindo o acompanhamento e o monitoramento via tabela de procedimentos do SUS, mas não agrega recurso financeiro ao registro. $\mathrm{O}$ discurso dos entrevistados aponta o reconhecimento de que grande parte das dificuldades enfrentadas pela PNPIC em seu processo de institucionalização decorre da não existência de financiamento indutor. A urgência em aprovar a política parece ter pesado na decisão de editá-la sem recurso específico, o que reforça a existência de tensionamentos administrativos no Ministério da Saúde e não unaminidade no discurso legitimador das PICS.

O modelo de financiamento das PICS atualmente está atrelado ao bloco de financiamento de média e alta complexidade, cujo impacto para os municípios se reflete no pressuposto de que os serviços de PICS estejam inseridos neste nível de assistência. Tal premissa não é compatível com o o crescimento que vem sendo observado na oferta de PICS em todo o país, uma vez que ele ocorre com maior expressão na Atenção Primária (SOUSA; TESSER, 2017), apesar de algumas racionalidades, como a homeopatia, por exemplo, terem apresentado redução na oferta no SUS, por dificuldade de integração neste nível de atenção em saúde (SOUSA et al., 2012).

\section{Consideraçóes finais}

Assumir as PICS como eixo importante no processo de redefinição do modelo de atenção em saúde significa questionar a hegemonia do paradigma biomédico, tecnicista e hospitalar que marcou os rumos da política de saúde nos anos 1990. 
Tal questionamento estaria implícito nas recorrentes resoluçôes sobre PICS nas Conferências de Saúde, no período analisado.

A PNPIC integra a agenda da política de saúde, porém foi aprovada após resistências, cujos desdobramentos repercutem nas açôes subsequentes na condução federal: temas centrais como o exercício profissional e necessidade de financiamento indutor, entre outros, persistem como pautas que demandam açôes governamentais no processo político de institucionalização das PICS. Os mecanismos de regulamentação da política estão circunscritos à visibilidade e monitoramento da oferta de serviços, o que revela uma estrutura ainda frágil de ampliação na implantação dessas práticas.

A integração das PICS no SUS não deveria limitar-se à adição de mais procedimentos advindos de racionalidades externas à biomedicina, e sim contribuir para a produção de mudanças no cuidado e no cotidiano dos serviços em saúde.

O cenário de crescimento de uso e oferta de serviços de PICS náo garantiu que as mesmas conseguissem conquistar espaço em pautas prioritárias da política de saúde brasileira. Para tanto, são importantes açóes governamentais capazes de produzir impacto nas práticas sociais. Do contrário, a PNPIC permanecerá marcada por fragilidade e sua existência circunscrita ao delineamento normativo institucional. ${ }^{1}$

\section{Referências}

BARROS, N. F.; SIEGEL, P.; DE SIMONI, C. Política Nacional de Práticas Integrativas e Complementares no SUS: passos para o pluralismo na saúde. Cadernos de Saúde Pública, Rio de Janeiro, n. 23, v. 12, p. 3066-3069, 2007.

BODEKER, G.; BURFORD, G. Traditional, Complementary and Alternative Medicine: policy and public health perspectives. Oxford: Imperial College Press, 2007.

BRASIL. Ministério da Saúde. Conferência Nacional de Ciência, Tecnologia e Inovação em Saúde, 2., 2005. Relatório final... Brasília: Ministério da Saúde, 2005.

. Ministério da Saúde. Conferência Nacional de MEDICAMENTOS E ASSISTÊNCIA FARMACÊUTICA, 1., 2005. Relatório final... Brasília: Ministério da Saúde, 2005.

. Ministério da Saúde. Conferência Nacional de Saúde, 10., Relatório final... Brasília: Ministério da Saúde, 1998.

. Ministério da Saúde. Conferência Nacional de Saúde, 11., Relatório final... Brasília: Ministério da Saúde, 2001.

. Ministério da Saúde. Conferência Nacional de Saúde, 12., Relatório final... Brasília: Ministério da Saúde, 2004. 
. Ministério da Saúde. Conferência Nacional de Saúde, 8., Relatório final... Brasília: Ministério da Saúde, 1987.

- Ministério da Saúde. Conferência Nacional de Vigilância Sanitária, 1., Relatório final... Brasília: Ministério da Saúde, 2001.

- Ministério da Saúde. Conselho Nacional de Saúde. Ata da 160a reunião ordinária do Conselho Nacional de Saúde, Brasília, 2005a. Disponível em: <http://conselho.saude.gov.br/>. Acesso em: 16 jun. 2016.

. Ministério da Saúde. Conselho Nacional de Saúde. Ata da 161a reunião ordinária do Conselho Nacional de Saúde, Brasília, 2005b. Disponível em: <http://conselho.saude.gov.br/>. Acesso em: 16 jun. 2016.

- Ministério da Saúde. Departamento de Atenção Básica. Política Nacional de Práticas Integrativas e Complementares no SUS. Brasília, DF 2006a. (Série B - Textos Básicos de Saúde).

- Ministério da Saúde. Departamento de Atenção Básica. Práticas integrativas e complementares: plantas medicinais e fitoterapia na Atenção Básica. Brasília, DF, 2012b. (Série A. Normas e Manuais Técnicos Brasília. Cadernos de Atenção Básica, n. 31).

- Ministério da Saúde. Diagnóstico da Inserção das Medicinas Naturais e Práticas Complementares no SUS. In: CONGRESSO BRASILEIRO DE HOMEOPATIA, 27., 2004. Brasília. Anais... Brasília, 2004.

. Ministério da Saúde. Diretrizes dos Núcleos de Apoio à Saúde da Família. Brasília, DF, 2009a. (Série B. Textos Básicos de Saúde. Cadernos de Atenção Básica, n. 27).

. Ministério da Saúde. Política Nacional de Medicina Natural e Práticas Complementares. Brasília, DF, 2005. Disponível em: <http://dtr2004.saude.gov/susdeaz/instrumento/arquivo/15_ resumo_mnpc.pdf >. Acesso em: 12 fev. 2016.

- Ministério da Saúde. Portaria no 702, de 21 de março de 2018. Altera a Portaria de Consolidação no 2/GM/MS, de 28 de setembro de 2017, para incluir novas práticas na Política Nacional de Práticas Integrativas e Complementares - PNPIC, Brasília, 2018a.

. Ministério da Saúde. Portaria no 1.230, de 14 de outubro de 1999. Inclui consultas médicas em homeopatia e acupuntura na tabela de procedimentos do Sistema de Informaçóes Ambulatoriais - SIA/SUS. Disponível em: <http://bvsms.saude.gov.br/bvs/saudelegis/gm/1999/ prt1230_14_10_1999.html.>. Acesso em: 07 abr. 2016.

. Ministério da Saúde. Portaria $n^{\circ} 145$, de 11 de janeiro de 2017. Altera procedimentos na Tabela de Procedimentos, Medicamentos, Órteses, Próteses e Materiais Especiais do SUS para atendimento na Atenção Básica, 2017a. Disponível em:<http://www.lex.com.br/ legis_27275941_PORTARIA_N_145_DE_11_DE_JANEIRO_DE_2017.aspx>. Acesso em: 10 abr. 2017. 
. Ministério da Saúde. Portaria no 154, de 24 de janeiro de 2008. Cria os Núcleos de Apoio à Saúde da Família - NASF, 2008. Disponível em: < http://bvsms.saude.gov.br/bvs/ saudelegis/gm/2008/prt0154_24_01_2008.html>. Acesso em: 16 de dez. 2016.

Ministério da Saúde. Portaria no 4.217, de 28 de dezembro de 2010. Aprova as normas de financiamento e execução do Componente Básico da Assistência Farmacêutica. Brasília, DF, 2010. Disponível em: <http://bvsms.saude.gov.br/bvs/saudelegis/gm/2010/ prt4217_28_12_2010.html>. Acesso em: 18 dez. 2016.

- Ministério da Saúde. Portaria $n^{\circ} 84$, de 25 de março de 2009. Adequa o serviço especializado 134 - Serviço de práticas integrativas e sua classificação 001 - Acupuntura, 2009b. Disponível em: <http://bvsms.saude.gov.br/bvs/saudelegis/sas/2009/prt0084_25_03_2009. html>. Acesso em: 10 jan. 2017.

. Ministério da Saúde. Portaria no 849, de 27 de março de 2017. Inclui a Arteterapia, Ayurveda, Biodança, Dança Circular, Meditaçáo, Musicoterapia, Naturopatia, Osteopatia, Quiropraxia, Reflexoterapia, Reiki, Shantala, Terapia Comunitária Integrativa e Yoga à Política Nacional de Práticas Integrativas e Complementares, 2017b. Disponível em:<http://www. lex.com.br/legis_27357131_PORTARIA_N_849_DE_27_DE_MARCO_DE_2017.aspx>. Acesso em: 10 abr. 2017.

. Ministério da Saúde. Portaria no 853, de 17 de novembro de 2006. Inclui na Tabela de Serviços/classificaçóes do Sistema de Cadastro Nacional de Estabelecimentos de Saúde - SCNES de Informaçóes do SUS, o serviço de código 068 - Práticas Integrativas e Complementares, 2006b. Disponível em: <http://189.28.128.100/dab/docs/legislacao/portaria853_17_11_06. pdf $>$. Acesso em: 10 set. 2016.

- Ministério da Saúde. Relação nacional de ações e serviços de saúde - RENASES. $1^{\mathrm{a}}$ versão, Brasília, 2012a. Disponível em: <http://conitec.gov.br/images/Protocolos/Renases2012. pdf>. Acesso em: $23 \mathrm{dez} .2016$.

. Ministério da Saúde. Relação Nacional de Medicamentos Essenciais: RENAME, 9. ed, Brasília, 2015. Disponível em: <http://bvsms.saude.gov.br/bvs/publicacoes/relacao_nacional_ medicamentos_essenciais_rename_2014.pdf> Acesso em: 18 mar. 2016.

. Ministério da Saúde. Secretaria de Atenção à Saúde. Departamento de Atenção Básica. Manual de implantação de serviços de práticas integrativas e complementares no SUS. Brasília: MS, 2018b. 56 p.

BRAVO, M. I. S. A Política de Saúde no Brasil. In: MOTA, A. E. S. et al. (Org.). Serviço social e saúde: formação e trabalho profissional. São Paulo: Cortez, 2006. p. 1-24.

CAPELLA, A. C. Perspectivas teóricas sobre o processo de formulação de políticas públicas. In: HOCHMAN, G.; ARRETCHE, M.; MARQUES, E. (Org.). Politicas públicas no Brasil. Rio de Janeiro: Editora Fiocruz, 2007. p. 87-122. 
CÔRTES, S. V. Sistema Único de Saúde: espaços decisórios e a arena política de saúde. Cad. Saúde Pública, Rio de Janeiro, n. 25, v. 7, p. 1626-1633, 2009.

JUSTO, C. M. P.; GOMES, M. H. A. A cidade de Santos no roteiro da expansão da homeopatia nos serviços públicos de saúde no Brasil. História, Ciências e Saúde, v. 14, n. 4, p. 1159-1171, 2007.

KINGDON, J. W. Agendas, Alternatives, and Public Policies. Glenview: Pearson Education, 2011. KODURU, S.; GRIERSON, D.; AFOLAYAN, A. Ethnobotanical information of medicinal plants used for treatment of cancer in the Eastern Cape Province, SouthAfrica. Cur SciBangalore, v. 92, n. 7, p. 906, 2007.

LUZ, M. T. Contribuição do conceito de racionalidade médica para o campo da saúde: estudos comparativos de sistemas médicos e práticas terapêuticas. In: LUZ M. T.; BARROS N. F. (Org.). Racionalidades médicas e práticas integrativas em saúde: estudos teóricos e empíricos. Rio de Janeiro: UERJ/IMS/Lappis, 2012. p. 15-24.

LUZ, M. T. Cultura contemporânea e medicinas alternativas: novos paradigmas em saúde no fim do século XX. Physis: Rev. Saúde Coletiva, v. 15, sup. p. 145-176, 2005.

MOEBUS, R. L. N.; NUNES, L. M. A. O. Das práticas integrativas a uma saúde simétrica. Diversitates International Journal, v. 7, n. 2, p. 67-70, 2015.

NASCIMENTO, M. C. et al. A categoria racionalidade médica e uma nova epistemologia em saúde. Ciência \& Saúde Coletiva, v. 18, n. 12, p. 3395-3604, 2013.

ORGANIZAÇÃO MUNDIAL DA SAÚDE. Conferência Internacional sobre Cuidados Primários de Saúde, 1978. Declaração de Alma-Ata. Alma Ata, Cazaquistão, 1978.

ORGANIZAÇÃO MUNDIAL DA SAÚDE. Estrategia de La OMS sobre Medicina Tradicional (2014-2023). Genebra: OMS, 2013.

ORGANIZAÇÃO PANAMERICANA DA SAÚDE. Estrategia de la OMS sobre medicina tradicional 2002-2005. Ginebra: WHO/EDM/TRM, 2002. 78 p.

RÉCIO, E. J. P. A influência da utilização de plantas medicinais nos custos do tratamento de agravos atendidos pela assistência farmacêutica básica. 2010. Dissertação (mestrado) - Universidade Federal do Pará, Belém, 2010.

RROS, N. F. Racionalidades médicas e práticas integrativas em saúde: uma análise sóciohistórica e suas relaçóes com a cultura atual. In: CAMPOS, G. S. et al. (Org.). Tratado de Saúde Coletiva. São Paulo: Editora Hucitec, 2012. p. 317-340.

SABATIER, P. A.; WEIBLE, C. The advocacy coalition framework: innovations and clarifications. In: SABATIER, P. Theories of the Policy Process. Denver: Westview Press, 2014.

SANTOS, F. A. S. et al. Política de práticas integrativas em Recife: análise da participação dos atores. Rev Saúde Pública, v. 45, p. 1154-9, 2011. 
SANTOS, M. C.; TESSER, C. D. Um método para a implantação e promoção de acesso às Práticas Integrativas e Complementares na Atenção Primária à Saúde. Revista Ciência e Saúde Coletiva, Rio de Janeiro, n. 17, v. 11, p. 3011-3024, 2012.

SECCHI, L. Políticas públicas: conceitos, esquemas de análise casos práticos. São Paulo: Cengage Learning, 2015.

SILVA, E. D. C.; TESSER, C. D. Experiência de pacientes com acupuntura no Sistema Único de Saúde em diferentes ambientes de cuidado e (des)medicalização social. Cadernos de Saúde Pública, Rio de Janeiro, v. 29, n. 11, p. 2186-2196, 2013.

SOUSA, I. M. C. et al. Práticas integrativas e complementares: oferta e produção de atendimentos no SUS e em municípios selecionados. Cad. Saúde Pública. Rio de Janeiro, v. 28, n. 11, p. $2143-$ 2154, 2012.

SOUSA, I. M. C. ; TESSER, C. D. Medicina Tradicional e Complementar no Brasil: inserção no Sistema Único de Saúde e integração com a atenção primária. Cad. Saúde Pública, v. 33, n. 1, p. 1-15, 2017.

SOUSA, I. M. C. Medicinas tradicionais alternativas e complementares e sua estruturação na Atenção Primária: uma reflexão sobre o cuidado e sua avaliação. 2013. Tese (doutorado em Saúde Pública) - Escola Nacional de Saúde Sérgio Arouca, Fundação Oswaldo Cruz, Rio de Janeiro, 2013.

STEKELENBURG, J. et al. Health care seeking behaviour and utilisation of traditional healers in Kalabo, Zambia. Health Policy, v. 71, n. 1, p. 67-81, 2005.

TESSER; C. D.; SOUSA, I. M.C.; NASCIMENTO, M. C. Práticas Integrativas e Complementares na Atenção Primária à Saúde brasileira. Saúde debate, v. 42, n. 1, p. 174-188, 2018.

\section{Nota}

${ }^{1}$ G. K. F. da Silva realizou a concepção e delineamento da pesquisa, coleta, análise e interpretação dos dados e redação original do artigo. I. M. C. de Sousa participou da concepção da pesquisa, delineamento metodológico, discussão e revisão crítica do conteúdo. M. E. G. da S. Cabral e M. B. L. Guimarães foram responsáveis pela revisão crítica do conteúdo e revisão textual do artigo. A. F. B. Bezerra realizou participou da discussão e revisão do artigo. 


\section{Abstract}

\section{National Policy on Integrative and Complementary Practices: trajectory and challenges in 30 years of SUS}

This article analyzes the construction and development of the National Policy on Integrative and Complementary Practices (NPICP) in SUS and its background. The study involved literature review, documentary analysis, and interviews with key actors in the policy building and implementation process. It was based on Kingdon's multi-flow model with regard to the formulation of the political agenda. The results point to important moments in the policy trajectory: influence of international parameters; role of national health conferences in building social demand; initial experiences of supply in the public network; protagonism in teaching and research; entry into the political agenda; federal leadership and challenges to institutionalization. The formulation of the NPICP is based on the pressure of strategic actors who undertook actions under favorable institutional conditions within the scope of the Ministry of Health after political change within the Federal Government in 2003, creating a window of political opportunity. This process was marked by resistance stemming from biomedical rationality and disputes of interest. Despite advances in the dissemination and visibility of service provision, actions under federal driving were not accompanied by significant changes in the training of professionals and in hegemonic health practices.

Keywords: traditional medicine; complementary therapies; public policies; Brazilian health policy. 